В результате, из рисунка 4 можно наблюдать графики переходных процессов работы датчика, в зависимости от расстояния датчики и возмущающего элемента. Чем ближе проходит возмущающий элемент к датчику, тем раньше срабатывает датчик. Тот же эффект можно наблюдать в момент выхода возмущающего из зоны действия датчика. Эффект насыщения проявляется и в этом случае, датчик позже реагирует на отдаление элемента.

Проведенные исследования и полученные данные рекомендуется использовать для моделирования систем автоматизированного управления и в программируемых устройствах автоматики в типовых производственных механизмах и комплексах.

$$
* * *
$$

1. Gorozhankin, A.N., Semenova, K.D., Nikiforova, E.A. \& Savosteenko, N.V. 2019, "Methods and test equipment of technological information sensors", IOP Conference Series: Earth and Environmental Science.

2. Борисов, А.М. Основы автоматики: учебное пособие / А.М. Борисов, Р.З.Хусаинов. - Челябинск: Изд-во ЮУрГУ, 2015. - 85 c.

3. Holtz J 2002 Sensorless control of induction motor drives Proceedings of the IEEE 90 (8), 1359-1394

4. https://simintech.ru/

\title{
Молочков В.Я., Молочков Д.В. \\ Методы и средства измерения влажности воздушных сред производственных помещений промысловых судов
}

Дальневосточный государственный рыбохозяйственный университет

(Россия, Владивосток)

doi: 10.18411/trnio-12-2021-150

\section{Аннотация}

В работе предлагается первичный измерительный преобразователь и измерительное цифровое дистанционное устройство для измерения влажности воздушных сред в производственных и натурных условиях на судах.

Данное устройство выполнено в соответствии с требованиями Российского Морского Регистра Судоходства и может использоваться в производственных условиях рыбодобывающих и рыбоперерабатывающих судов и для исследования Океана.

Ключевые слова: промысловые суда, измерения, влажность.

\section{Abstract}

The paper proposes a primary measuring transducer and a digital measuring remote device for measuring the humidity of air in industrial and natural conditions on ships.

This device is made in accordance with the requirements of the Russian Maritime Register of Shipping and can be used in the industrial conditions of fishing and fish processing vessels and for the exploration of the Ocean.

Keywords: fishing vessels, measurements, humidity.

\section{1. Выбор первичного измерительного преобразователя}

В настоящее время методы и устройства измерения влажности воздуха имеют существенную методическую и аппаратную проработку. Однако, при анализе существующих устройств видно, что область измерений характерная для рыбопромысловых, рыбообрабатывающих и научно-исследовательских судов имеет совокупность требований, из-за которых во многих случаев невозможно применить существующие устройства.

К основным требованиям относятся требования Российского Морского Регистра Судоходства к судовой измерительной аппаратуре. Они обусловлены спецификой условий работы на судах. Для стационарных измерительныхъ устройств на судне необходима информационная связь с судовыми информационно-управляющими системами, как, в данном случае с Data Chief C20

Следует учесть так же очень жесткие условия эксплуатации таких датчиков измерителей в агрессивной среде, что делает проблему их создания сложной технической задачей. 
При измерении относительной влажности по массе сконденсировавшейся воды необходимо одновременно измерять температуру воздуха, так как относительная влажность в процентах зависит от температуры воздуха.

Данные условия определяют выбор датчика, его конструкции и электрической схемы измерителя.

В данной разработке для измерения влажности и температуры применены кварцевые резонаторы. Для датчика влажности два с АТ срезом и для измерителя температуры кварцевый резонатор с У срезом.

Выход информации от датчиков ВЧ сигналом, что позволяет разнести датчик, измерительную и регистрирующую части.,

2. Структурная схема измерителя

Структурная схема индукционного измерителя солености морской воды состоит из трех основных частей: высокочастотной, аналоговой и цифровой и приведена на рисунке 1. Информация о влажности по динии CAN перелается на ЭВМ информационно-управляющей судовой системы Data Chief C20.

Измеритель состоит из следующих устройств часть состоит из следующих узлов, показанных на структурной схеме:

— д датчика влажности, выполненного на двух кварцевых резонаторах частотой 5 МГц с АТ-срезом:

- датчика температуры на кварцевом резонаторе с У-срезом

- преобразователей частота-напряжение;

- аналого-цифрового преобразователя с выходом на CAN канал для дистанционной передачи информации;

- транскодер CAN-RS-232S для ввода информации в ЭВМ через COM-порт.

Такой набор позволяет располагать измерительную часть в необходимом месте и без потерь передавать в реальном масштабе времени измерительную информацию по линии CAN в пределах судна.

Работа схемы происходит следующим образом.

Датчик влажности имеет контакт с воздушной средой и выполнен на двух кварцевых резонаторах.

Один резонатор герметичен и выдает стабильную частоту 5 МГц, второй резонатор безкорпусной и покрыт влаго абсорбирующей пленкой. Частота второго резонатора зависит от объема влаги на пленке т.е. он работает как первичный измерительный преобразователь. Разность частот двух резонаторов пропорциональна абсолютной влажности.

Для получения относительной влажности используется специальный резонатор с Усрезом, кварцевый резонатор, частота которого зависит от температуры.

Получение окончательного результата об относительной влажности производится двумя способами;

- с п помощью ЭВМ, так как это удобно для стационарного варианта измерителя в условиях судна;

- $\quad$ аппаратный схемный вариант для переносного с цифровой индикацией.

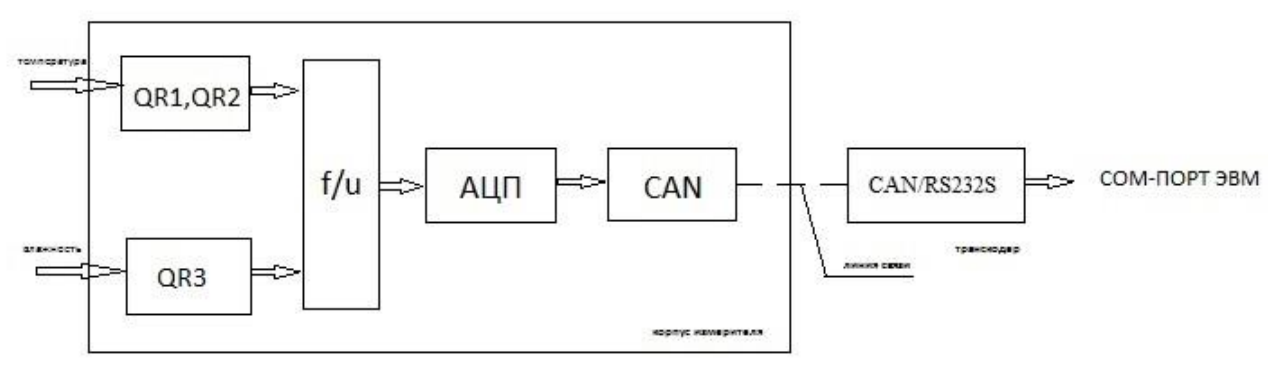

Рисунок 1. Структурная схема стаџионарного варианта судового измерителя влажности воздуха 
3. Конструктивные особенности измерителя

Требования к конструкции измерителя состоят из следующих составляющих:

- требования Российского Морского Регистра Судоходства, т.2, 2005 год, как ко всем устройствам, используемым на судах;

- требования, обусловленные типом первичного измерительного преобразователя - датчика;

- х характером обработки и использования измерительной информации;

- условиями использования на промысловых, рыбоперерабатывающих и исследовательских судах;

- способом передачи, обработки и фиксации измерительной информации.

На основе анализа всех требований разработано измерительное устройство с дистанционной передачей измерительной информации с защитой от внешних влияний IP56.

Измеритель использовался как в условиях судовых помещений, так и в натурных морских условиях на научно-исследовательских судах в экспедиционных условиях проведения исследований Тихоокеанским океанологическим институтом ДВНЦ.

Конструкция измерительной части стационарного варианта измерителя выполнена в брызгозащищенном, цилиндрическом корпусе с этажеркой электроники в цилиндрической части корпуса и кварцевыми резонаторами в верхней части. Устройство имеет разъем и варианты крепления.

Внешний вид варианта конструкции для натурных исследований на судах приведен на фотографии, Рисунок 2.

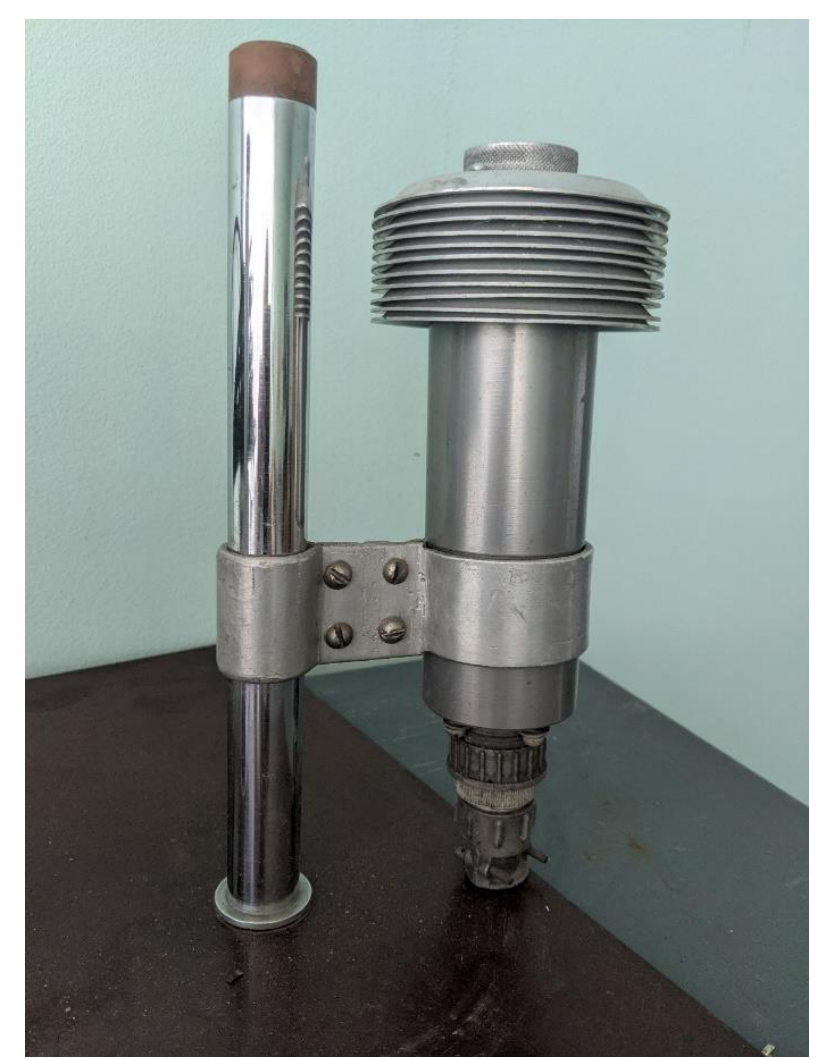

Рисунок 2. Внешний вид конструкции стационарного варианта измерителя влажности для нетурньх морских исследований

$* * *$

1. Молочков В.Я. Микропроцессорные системы управления техническими средствами рыбопромысловых судов: Уч.пос. Москва: Моркнига, 2013. -362 с.

2. Кирюха В.В. Датчики в системах автоматики: Уч. пос. Владивосток:Дальрыбвтуз, 2001. - 95 с.

3. Карандеев К.Б. Специальные методы электрических измерений. - М.: Госэнерго-издат, 1983. - 370 с. 